\title{
Micro-Epidemiological Investigation of Echinococcus multilocularis in Wild Hosts from an Endemic Area of Southwestern Hungary
}

\author{
Tibor Halász ${ }^{1,2}$, Gábor Nagy 1,3,* István Nagy ${ }^{3,4}$ and Ágnes Csivincsik ${ }^{1,3}$ \\ 1 Institute of Physiology and Animal Nutrition, Kaposvár Campus, Hungarian University of Agriculture and \\ Life Sciences, H-7400 Kaposvár, Hungary; halasz.tibor@sefag.hu (T.H.); csivincsik.agnes@uni-mate.hu (Á.C.) \\ 2 Somogy County Forest Management and Wood Industry Share Co., H-7400 Kaposvár, Hungary \\ 3 One Health Working Group, Kaposvár Campus, Hungarian University of Agriculture and Life Sciences, \\ H-7400 Kaposvár, Hungary; nagy.istvan.prof@uni-mate.hu \\ 4 Institute of Animal Husbandry, Kaposvár Campus, Hungarian University of Agriculture and Life Sciences, \\ H-7400 Kaposvár, Hungary \\ * Correspondence: gabor.nagy.oh@gmail.com
}

check for updates

Citation: Halász, T.; Nagy, G.; Nagy, I.; Csivincsik, Á. Micro-Epidemiological Investigation of Echinococcus multilocularis in Wild Hosts from an Endemic Area of Southwestern Hungary. Parasitologia 2021, 1 , 158-167. https://doi.org/10.3390/ parasitologia1030017

Academic Editor: Maria Victoria Periago

Received: 22 July 2021

Accepted: 31 August 2021

Published: 1 September 2021

Publisher's Note: MDPI stays neutral with regard to jurisdictional claims in published maps and institutional affiliations.

Copyright: (c) 2021 by the authors. Licensee MDPI, Basel, Switzerland. This article is an open access article distributed under the terms and conditions of the Creative Commons Attribution (CC BY) license (https:/ / creativecommons.org/licenses/by/ $4.0 /)$.

\begin{abstract}
Echinococcus multilocularis is a tapeworm causing severe zoonotic disease in temperate Europe. Between 2018 and 2020, 68 golden jackals and 94 red foxes were investigated to determine the prevalence of E. multilocularis infection and its driving factors. The overall prevalence (golden jackal: $41.2 \%$; red fox: $12.5 \%$ ) significantly differed, whereas the mean intensities did not. The spatial scan statistics revealed three significant clusters of E. multilocularis infection. The binary logistic and ordinal regression results revealed that the golden jackal is more likely to become infected than the red fox, and the probability of infection level was also higher in jackals. Our findings highlight the golden jackal's role, which could be as important as the red fox in the spread of this severe zoonotic agent. This micro-epidemiological approach can advance the knowledge on local drivers which facilitate the spread of E. multilocularis and could cause a relevant public health problem on the continent.
\end{abstract}

Keywords: Echinococcus multilocularis; golden jackal; red fox; micro-epidemiology

\section{Introduction}

Echinococcus multilocularis is a tapeworm causing a severe zoonotic disease, human alveolar echinococcosis (AE). With the lack of appropriate treatment, it is fatal in humans. In recent years, official reports revealed that the disease has spread across Europe with an increasing number of cases. At the end of the 1980s, the disease was endemic only in France, Germany, Switzerland, and Austria [1]. After 30 years, human alveolar echinococcosis has already been reported in 25 European countries [2]. Among others, this fact called into being the Directive 2003/99/EC of the European Parliament and of the Council, which regulates the monitoring of zoonoses and zoonotic agents, including E. multilocularis in all European Union (EU) member states. Until the mid-2010s, the Hungarian Zoonoses Monitoring for European Food Safety Authority (EFSA) served detailed data on the human and animal E. multilocularis incidence [3]. Unfortunately, in the last few years, the Hungarian monitoring is not as intensive even though the number of AE cases might be increasing in Hungary [2,4].

In the temperate region of Europe, the red fox (Vulpes vulpes) is the principal definitive host. Other carnivores, such as the Arctic fox (Vulpes lagopus), the raccoon dog (Nyctereutes procyonoides), and the golden jackal (Canis aureus) have a lesser role in the sylvatic life-cycle of E. multilocularis [5]. It is accepted that the spread of E. multilocularis from its historical endemic area towards each direction across the continent is due to the successful rabies 
control campaigns, which, as a consequence, led to the expansion of the red fox population [6]. In some European areas, the elevated densities of fox populations contributed to the establishment of self-sustaining urban fox populations within villages and towns. Nowadays, the rapid conurbation strengthens further urbanization of the foxes. This phenomenon could contribute to an elevated parasite biomass within the human settlements of the endemic areas and may lead to an increased incidence of human AE [7].

In previous studies (2008-2009 and 2012-2013) conducted in Hungary in the red fox, the overall E. multilocularis infection rate was $10.7 \%$ and $7.9 \%$, respectively [8], while an unusually high prevalence $(15.6 \%)$ was found in golden jackal [9]. Therefore, our aims were to (1) reveal the presence of E. multilocularis in two sympatric carnivore species at a local level in southwestern Hungary, and (2) to determine the driving factors in infection dynamics.

\section{Results}

The molecular analysis confirmed that all of the isolated Echinococcus specimens were Echinococcus multilocularis (Supplementary Table S1).

The annual prevalence and mean intensity showed a continuous increase in both host species (Figure 1, Supplementary Tables S2 and S3). The overall prevalence of E. multilocularis in the fox population was $12.5 \%$ (95\% confidence interval; CI95\% $=7.15-20.72)$, while it proved to be $41.2 \%(\mathrm{CI} 95 \%=30.1-53.7)$ in the jackal. The mean intensity of infection was $1056.92(\mathrm{CI} 95 \%=217.83-4179.25)$ and $1679.96(\mathrm{CI} 95 \%=545.79-5205.86)$ in foxes and jackals, respectively. The overall prevalence significantly differed $(p<0.0001)$ between the two host species. In the case of mean intensity, we did not confirm statistical disparateness $(p=0.658)$.

The spatial scan statistic identified three significant clusters of E. multilocularis infection (Figure 2). Two of them were high-rated and contained 33 and 14 infected animals altogether. The third cluster, as low-rated, involved only four infected animals (Table 1).

Table 1. Geographic distribution of echinococcosis in wild carnivore populations of the study area.

\begin{tabular}{ccccccc}
\hline Cluster & $\begin{array}{c}\text { Radius } \\
\mathbf{( k m )}\end{array}$ & $\begin{array}{c}\text { Infected } \\
\text { Animals }\end{array}$ & $\begin{array}{c}\text { Non-Infected } \\
\text { Animals }\end{array}$ & RR * & LLR ** & $p$-Value \\
\hline $1^{* * *}$ & 2.89 & 33 & 38 & 6.18 & 17.32 & $<0.0001$ \\
2 & 4.77 & 4 & 77 & 0.13 & 16.38 & $<0.0001$ \\
3 & 2.02 & 14 & 8 & 3.48 & 9.09 & 0.001 \\
\hline * Relative risk; ${ }^{* *}$ Log likelihood ratio; ${ }^{* * *}$ Cluster1 (46.188961 N, $\left.17.801972 \mathrm{E}\right)$ & and Cluster3 (46.192778 N,
\end{tabular}

17.742061 E) = high-rated; Cluster2 (46.254833 N, 17.742878 E) = low-rated.

For E. multilocularis infection, seven variables were potential candidates for modelling infection/non-infection. The FOREST (proportion of forest covering) variable was rejected from the process because its variance inflation factor (VIF) value proved to be 11.23. Our final regression model (Akaike Information Criterion, AIC $=166.479$ ) had a moderate classification accuracy (Area Under the Curve, AUC $=0.69$ ) and was characterised by $75.6 \%$ overall accuracy in predicting the infection and contained only one explanatory variable SPEC (species). E. multilocularis infection status in the host species showed a positive connection. The odds ratio (OR) suggested the golden jackal was almost five times more likely to become infected than the red fox (Table 2). Of all other environmental factors, none proved to correlate with the infection status of the hosts by our model.

Using a negative binomial generalized linear model, the mean intensity proved to be independent of SPEC and all other investigated factors.

Ordinal regression analysis confirmed that the mean intensity also depended on the species of the host (SPEC), while other independent variables had no impact on it (Table 3). 
Table 2. Binary logistic regression for infection status of different host species $\left(\mathrm{N}_{\text {fox }}=94, \mathrm{~N}_{\text {jackal }}=68\right)$.

\begin{tabular}{ccccccc}
\hline Predictor & Coefficient & SD ${ }^{*}$ & $p$-Value & OR ${ }^{* *}$ & \multicolumn{2}{c}{ OR CI95\%*** } \\
\cline { 6 - 7 } & & & & Lower & Upper \\
\hline $\begin{array}{c}\text { SPEC }{ }^{* * * *} \\
\text { fox vs. jackal) }\end{array}$ & 1.59 & \pm 0.4 & $<0.0001$ & 4.9 & 2.26 & 10.63 \\
\hline CONSTANT & 0.58 & \pm 0.73 & 0.43 & 1.78 & & \\
\hline${ }^{*}$ Standard deviation, ${ }^{* *}$ Odds ratio, ${ }^{* * *} 95 \%$ confidence interval for odds ratio, ${ }^{* * *}$ Species as a variable.
\end{tabular}
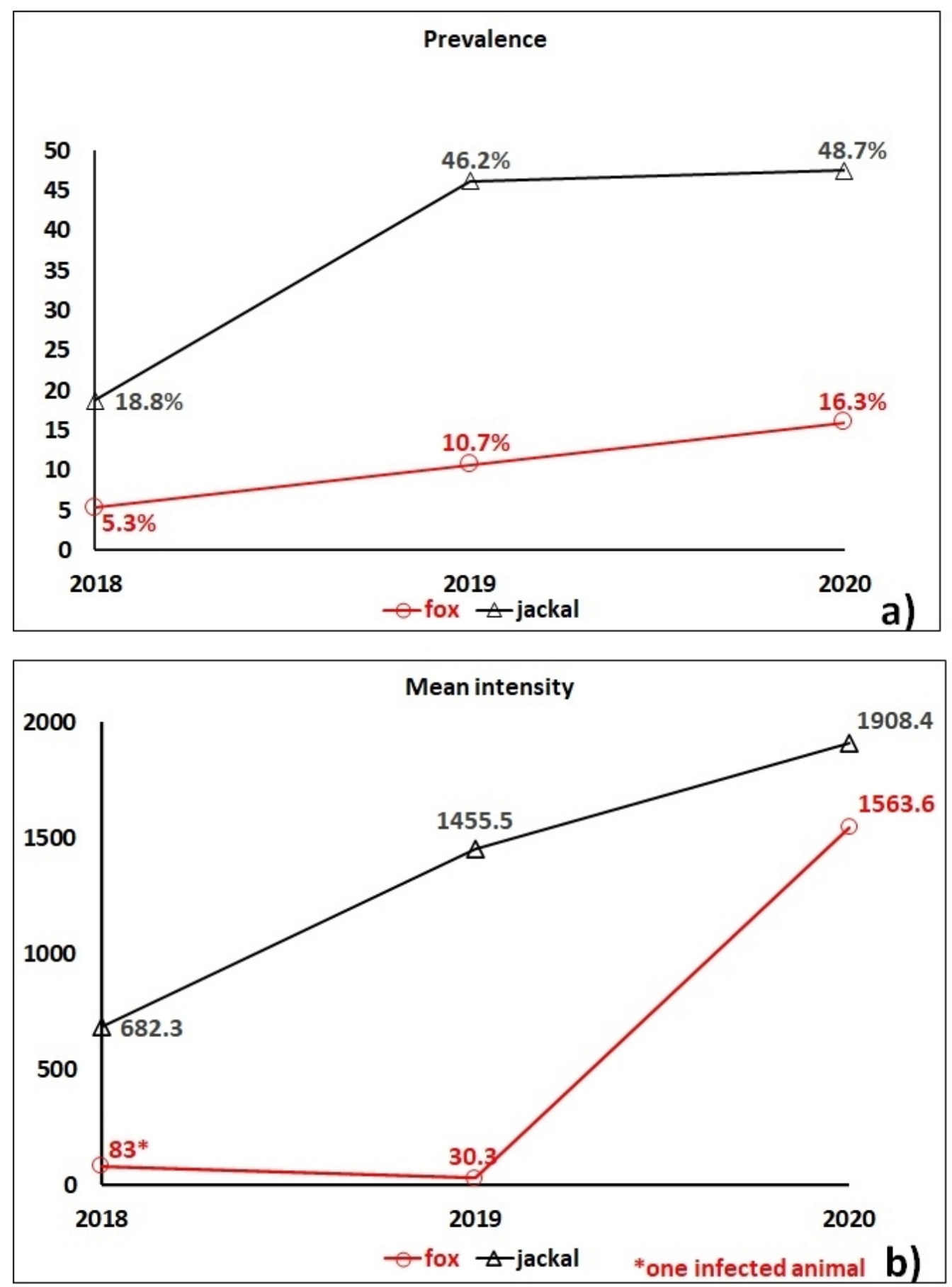

Figure 1. Annual prevalence (a) and mean intensity (b) of E. multilocularis in the red fox and golden jackal. Note: the mean intensity was calculated as the mean number of adult worms found in the intestines of infected animals. 


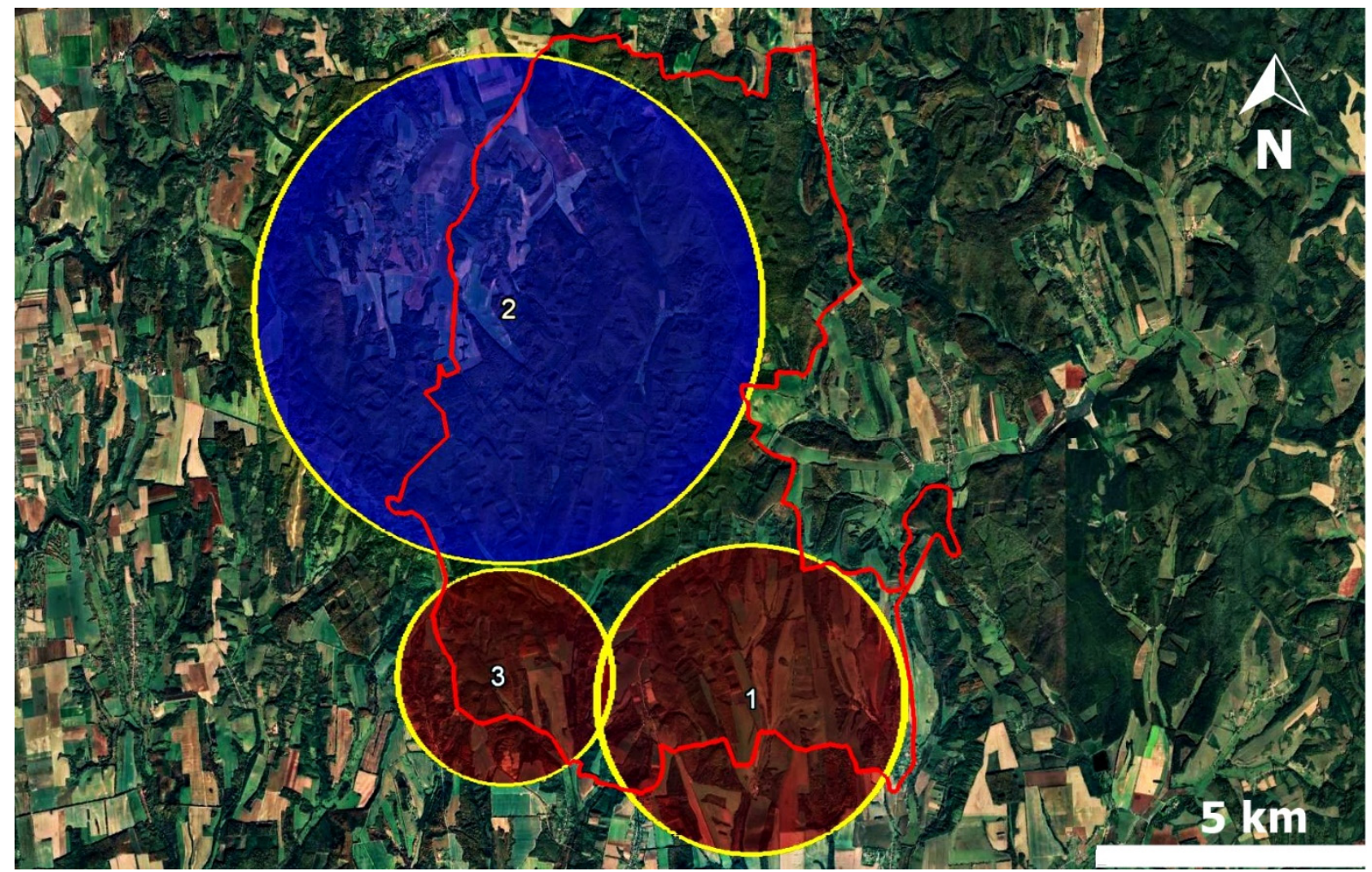

Figure 2. Significant clusters of E. multilocularis infection ( $\mathrm{red}=$ high-rated cluster E. multilocularis infection; blue = low-rated cluster of E. multilocularis infection). The study area is in Somogy County, Hungary. Central coordinates of the clusters: Cluster1 (46.188961 N, 17.801972 E), Cluster2 (46.254833 N, 17.742878 E), and Cluster3 (46.192778 N, 17.742061 E).

Table 3. Ordinal regression for infection level with golden jackal as a reference category of species variable.

\begin{tabular}{|c|c|c|c|c|c|c|}
\hline \multirow{2}{*}{ Predictor } & \multirow{2}{*}{ Coefficient } & \multirow{2}{*}{ SD * } & \multirow{2}{*}{$p$-Value } & \multirow{2}{*}{ OR ** } & \multicolumn{2}{|c|}{ OR CI95\% *** } \\
\hline & & & & & Lower & Upper \\
\hline $\mathrm{SPEC}_{\mathrm{fox}}{ }^{* * * *}$ & -1.71 & \pm 0.45 & $<0.0001$ & 0.18 & 0.07 & 0.44 \\
\hline
\end{tabular}

\section{Discussion}

Our results indicated that the wild carnivores' echinococcosis has become endemic in the studied microregion and revealed a high infection rate in both hosts. To our knowledge, this is the first report from Europe showing that the infection level of E. multilocularis in the golden jackal $(41.2 \%)$ has a similar pattern to that previously observed in foxes in highly endemic parts of western Europe [6]. Our findings on E. multilocularis prevalence in foxes were very similar to those of previous studies in Hungary [8].

In the case of the jackal, there are few European studies which have searched for echinococcosis in this definitive host. Previous studies showed a medium divergent prevalence with wide CI95\% $(15.6 \%$, CI95\% $=10.9-21.9 \%, 3.4 \%$, CI95\% $=1.8-16.9 \%$; $9.1 \%$, CI95\% $=0.47-40.4 \%$ and $14.3 \%$, CI95\% $=5.04-31.9 \%$ ) (see in [9-12]). On the other hand, these studies usually spanned more extended areas $\left(90,030 \mathrm{~km}^{2} ; 21,506 \mathrm{~km}^{2} ; 56,594 \mathrm{~km}^{2}\right)$ with a much lower sample size $(n=11 ; n=28 ; n=29)$ (see in 10-12). The present study revealed a considerably higher prevalence with a narrower $\mathrm{CI} 95 \%$ in the jackal. Our study's dataset is based on a relatively high sample size $(n=68)$ that originated from a relatively small area $\left(89.6 \mathrm{~km}^{2}\right)$. We suggest that the differences between the previous findings might be derived from the underrepresentation of both the hosts and the parasite. Our assumption could be supported by a local study conducted in Somogy 
County, Hungary [9]. By dissection of 173 golden jackals collected from $6065.1 \mathrm{~km}^{2}$, the authors observed a higher prevalence with a narrower CI95\% $(15.6 \%$, CI95\% $=10.9-21.9 \%)$ than previously found by others [10-12]. Although a small sample size does not bias the prevalence, it can be associated with an inflated C195\%. Therefore, a larger sample size is recommended to characterize the true infection rate [13]. We suggest that a microepidemiological investigation based on a larger sample size from a smaller study area may contribute to a more precise knowledge on the endemicity of this transmissible disease. This approach could help avoid underestimation and misconception and could aid in determining the role of the golden jackal in the E. multilocularis endemic from Europe.

The spatial scan approach identified significant clusters which demonstrated echinococcosis risk at a local level. A considerable deviation was experienced between the location of high- and low-rated clusters. We suppose that this result reflects on the golden jackal, which could be as suitable a host as the red fox to maintain and spread the worm. The outcome of the logistic regression analysis also supports this because the OR of SPEC showed that the jackal is five times more likely to become infected than the red fox. Both carnivores usually prefer diverse habitats and their feeding activity could be localized to meadows and pastures where their decisive preys (vole species) are abundant [14-16]. The high-rated Echinococcus clusters formed in areas where the mosaic-structured landscape was observed. On the other hand, a possible explanation of why the hotspots evolved is the rapid and widespread population expansion of common voles (Microtus arvalis) during exactly the study period [17]. In these conditions, jackals and foxes could consume a larger proportion of potential intermediate hosts, which resulted in an extremely high Echinococcus prevalence in Cluster1 and Cluster3 in both hosts. This hypothesis was strongly supported by the continuous increase of annual prevalence and mean intensity of E. multilocularis in both investigated host species in parallel with the vole's population expansion during the same study period.

The presence of interspecific competition between foxes and jackals could also support the formation of the clusters. Among predators, competitive interactions can affect the utilization of resources and modify the populations' success $[18,19]$. The presence of an apex predator eventuates spatial and/or temporal avoiding behavior in mesopredators. On the other hand, in the absence of an apex species, the larger mesopredator (jackal) might control smaller carnivores (fox) through interference and resource competition [20-22]. Several studies confirmed that the golden jackal could compete with the red fox either for food [23] or foraging sites [22,24,25]. Therefore, the separation between the two host populations could be manifested in a higher E. multilocularis prevalence in the jackal.

The emergence of human alveolar echinococcosis is well documented in Central Europe. The high prevalence in foxes and increasing numbers of human E. multilocularis infections show a strong correlation. It is generally believed that foxes are the main drivers of the environmental contamination with E. multilocularis eggs [26]. The findings of our micro-epidemiological approach highlight the golden jackal's role, which could be as important as the red fox in the spread of this severe zoonotic agent. The very dynamic expansion of this opportunistic carnivore could facilitate the spread of E. multilocularis and could cause a relevant public health problem on the European continent [27]. Albeit this novel epidemiological situation was observed in a small-scale habitat and involved a small number of carnivores, the prevalence and worm burden call attention to the raison d'être of micro-epidemiology and the importance of the multidisciplinary approach. The knowledge of small-scale epidemics and their place-specific factors make assessing their patterns possible [28]. Thus, information on fine-scale heterogeneity in drivers of transmission can serve a deeper understanding of the general epidemiology of E. multilocularis.

We have to emphasize that, in Hungary, echinococcosis is notifiable only in humans. In the lack of synchronized national and regional monitoring programs and health authorities' preventive recommendations, the epidemiological situation of E. multilocularis can be exacerbated. These facts and our results may draw attention to the importance of integrated national echinococcosis prevention programmes. 


\section{Materials and Methods \\ 4.1. Study Site}

On account of our moderate knowledge on the country-wide epidemic, we launched a local surveillance programme in a southwestern Hungarian region to observe the dynamics of E. multilocularis infection in golden jackal and red fox populations. In our investigation, we described the scale of the study site as "local" in accordance with Goodin et al. [29]. The area is a part of the South Transdanubian Hills. The extension of the area is $89.6 \mathrm{~km}^{2}$ (approximately $0.1 \%$ of the total area of Hungary) with highly forest-covered characteristics. Among the steep hills and narrow valleys, the area has a submediterranean climate (worm summer, relatively mild winter) with some submontaneous habitat patches $\left(10^{\circ} \mathrm{C}\right.$ a mean annual temperature and $630-800 \mathrm{~mm}$ annual precipitation). Forest cover is approximately $70 \%$ with a 6000 ha core monoblock woodland. Main species are oaks (Quercus spp.), limes (Tilia spp.), European beech (Fagus sylvatica), hornbeam (Carpinus betulus), and robinia (Robinia pseudoacacia). On the study site's peripheries, grasslands, arable lands, and wide creekbeds characterize the landscape. Within the area and directly around it, there are ten small villages with altogether about 3300 inhabitants (Figure 3).

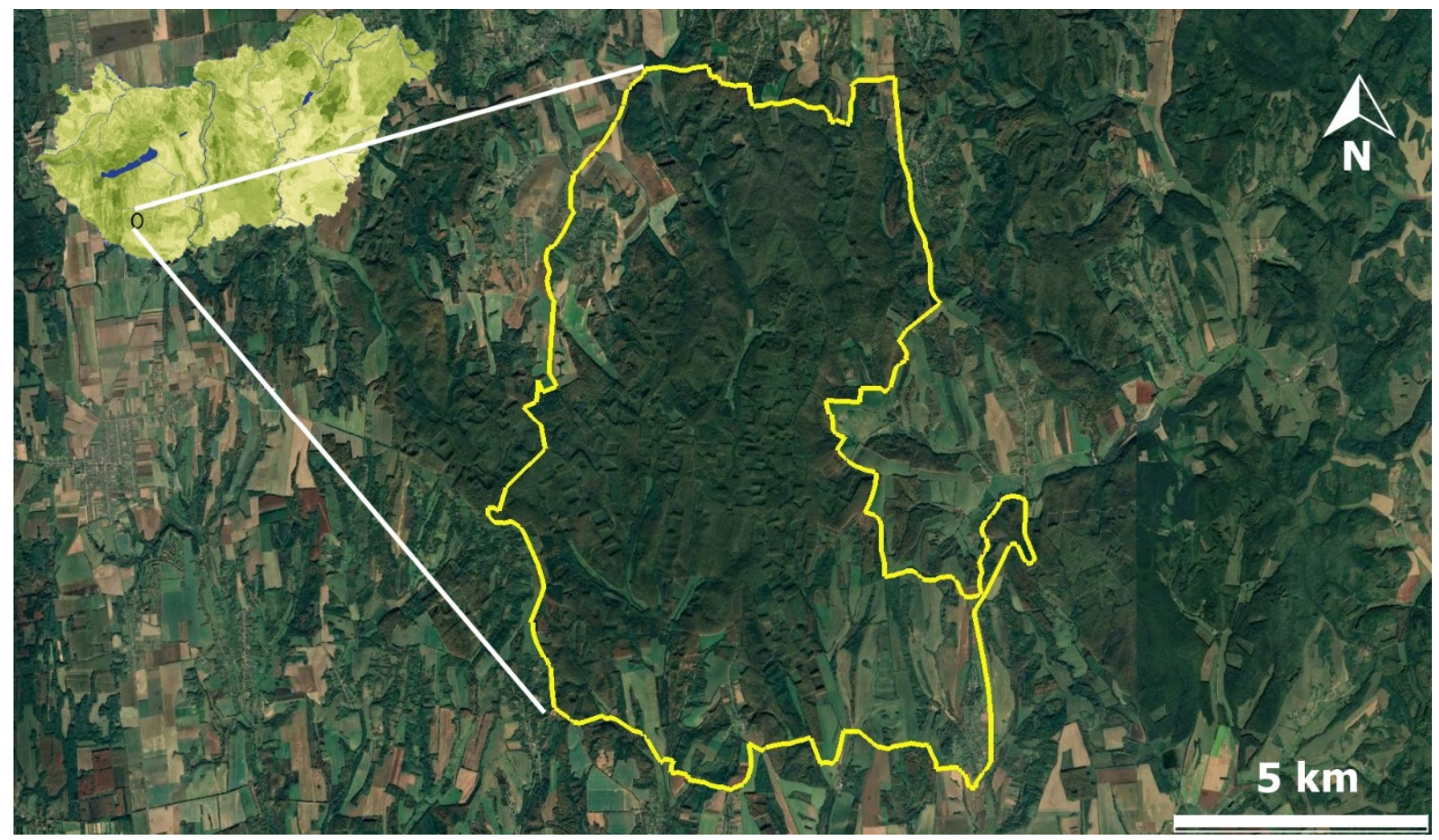

Figure 3. Location of sampling area: South Transdanubian Hills, Somogy County, Hungary.

\subsection{Parasitological Examination}

Between January of 2018 and December of 2020, 68 and 96 specimens of golden jackal and red fox, respectively, were sampled. The animals were legally hunted by the approved game management plan of the site. The sedimentation and counting technique were used to determine infection characteristics in both hosts [30]. The hunted animals were processed after five days of freezing at $-80^{\circ} \mathrm{C}$. After thawing, the small intestines were opened alongside the lumen and transferred into a plastic jar filled with $0.9 \% \mathrm{NaCl}$ solution. The gut mucosal layer was scrapped three times between fingers. The content was thoroughly stirred for $30 \mathrm{~s}$. After 15-min sedimentation, the supernatant decanted and the procedure was repeated 4-6 times until the supernatant became well transparent for parasite detection. The remaining sediment was examined in Petri dishes using a stereomicroscope at magnification $40 \times$. All worms were counted if up to 100 worms were found. In higher numbers, the remains filled up to $1 \mathrm{~L}$ and homogenised by stirring, and 
two $100 \mathrm{~mL}$ subsamples were taken. The total worm burden was calculated from the subsample count by multiplying the worm numbers by 5 . The collected isolated specimens were placed into $96 \%$ alcohol for preservation until DNA analysis.

\subsection{Molecular Diagnostic Method}

The DNA extraction was carried out using four individual worms from each infected animal, except for one jackal that had only two worms. The DNA lysates were made using $100 \mathrm{~mL}$ of Chelex 100 resin 5\% (Bio-Rad Laboratories, Hercules, CA, USA) solution at $95{ }^{\circ} \mathrm{C}$ for $20 \mathrm{~min}$. After cooling $\left(4^{\circ} \mathrm{C}\right)$, a 10 min centrifugation was implemented $(8000 \mathrm{rpm})$ and the supernatant containing extracted DNA (approximately $200 \mu \mathrm{L}$ was carefully pipetted into a new tube and stored at $-20^{\circ} \mathrm{C}$.

We applied the following primer sequences for taxonomy identification: Cest1: $5^{\prime}$ TGCTGATTTGTTAAAGTTAGTGATC-3 ${ }^{\prime}$; Cest2: $5^{\prime}$-CATAAATCAATGGAAACAACAACAAG-3' for E. multilocularis and Cest4: 5'-GTTTTTGTGTGTTACATTAATAAGGGTG-3'; Cest5: 5'-GCGGTGTGTACMTGAGCTAAAC-3' for E. granulosus s.l. The final volume of the reaction mix was $15 \mu \mathrm{L}$ and consisted of $7.5 \mu \mathrm{L}$ PCRBIO Taq Mix (PCR Biosystems, London, UK), $5.7 \mu \mathrm{L}$ distilled water, $0.2 \mu \mathrm{L}$ of each primer $(10 \mu \mathrm{M})$, and $1 \mu \mathrm{L}$ of sample DNA. The PCR cycling profile consisted of denaturation at $95{ }^{\circ} \mathrm{C}$ for $4 \mathrm{~min}, 40$ cycles of denaturation at $94{ }^{\circ} \mathrm{C}$ (for $30 \mathrm{~s}$ ), annealing at $58{ }^{\circ} \mathrm{C}$ (for $90 \mathrm{~s}$ ), and extension at $72{ }^{\circ} \mathrm{C}$ (for $10 \mathrm{~s}$ ), followed by a final extension at $72{ }^{\circ} \mathrm{C}$ for $4 \mathrm{~min}$. The PCR products resolved in $2 \%$ agarose gel stained with SYBR Green (ThermoFisher, Waltham, MA, USA) nucleic acid gel stain and visualized under UV light. Genotype determination was based on the fragment lengths such as $395 \mathrm{bp}$ for E. multilocularis and $117 \mathrm{bp}$ for E. granulosus s.l. [31].

\subsection{Spatial Cluster Analysis}

To assess the E. multilocularis infection, all shooting coordinates were recorded (Supplementary Table S4). For identification of the significant spatial clusters, if any, the SaTScan software (version 9.6.1, www.satscan.orgvers (accessed on 6 May 2021)) was used [32].

We inserted all shooting points into the $2.5 \times 2.5 \mathrm{~km}$ Universal Transverse Mercator (UTM) system $[33,34]$. The presence of the E. multilocularis in a host meant a 'case' while the non-infected animals formed the 'control' group. The analysis also included the center coordinate of the concerned UTM grids. We applied this approach to detect the high- and low-rate clusters of E. multilocularis infection cases. The detection of clusters was performed using a Bernoulli Model (purely spatial). The test of significance of the identified clusters is based on a likelihood ratio test and calculated for 999 Monte Carlo simulations with the maximum cluster size of $50 \%$ of the total population for parasites (as cases). We considered the most likely clusters in those areas associated with the maximum value of the likelihood ratio test statistics.

\subsection{Land Cover Data}

The different land cover presented on the study site was queried from the CORINE Land Cover 2018 dataset of land uses, made available through the Department of Geodesy, Remote Sensing, and Land Offices (http:/ / www.ftf.bfkh.gov.hu/portal/index.php/kezdoldal (accessed on 11 March 2021)). To evaluate the connection between E. multilocularis presence and the environmental factors first, we determine the home-range size of the hosts. We adapted other study results in both species and applied a circular buffer with a radius of $1400 \mathrm{~m}$ around the shot position [35,36]. A total of 25 different CORINE land cover categories were identified. We regrouped them into six categories (i.e., HUMAN, ARABLE, GRASS, MIXED, FOREST, WET) for the sake of simplicity in the later analyses (Supplementary Table S5). Before the statistical analysis, we calculated their proportion and used them as continuous variables. 


\subsection{Statistical Analysis}

We calculated the annual and overall prevalence and mean intensity in both species. Because the annual sample sizes were relatively small, we did not perform comparison between the host species. Comparing the overall prevalence and mean intensity in the two host species, the unconditional exact test and bootstrap 2-sample t-test were used, respectively $[37,38]$. This analysis was carried out by a QP web online software version 1.0.15 (http:/ / www2.univet.hu/ qpweb / qp10/index.php (accessed on 29 December 2020)) with a 95\% confidence interval (CI 95\%).

Binary logistic regression analysis was conducted with a backward stepwise selection to determine the association between collected variables and E. multilocularis infection. The explanatory variables were included/deleted by using a likelihood ratio test. Altogether, eight variables were initially inserted and tested in the model. We amended the six mentioned environmental variables with infection (INFECT; non-infected $=0$; infected $=1$ ), as a dependent variable and species (SPEC) as an independent one. As the SPEC was a categorical predictor (fox $=1$; jackal $=2$ ), the fox was assigned to a reference class. Before the analysis, we checked the variables' multicollinearity to eliminate the highly correlated explanatory variables. We rejected the variables with the highest variance inflation factor (VIF) value that exceeded ten [39]. Odds ratios (OR) and their CI 95\% were used to assess the presence and the strength of correspondence between the dependent and independent variables. Akaike's Information Criterion (AIC) was used for assessing different models; lower values indicated a better fitness for the data. The best model performance was assessed by using the area under the curve (AUC). We accepted the AUC score as a fair one if it was above 0.7 [40].

In the case of the mean intensity, we hypothesized that a negative binomial regression model or zero inflated negative binomial regression model could be applied because of the overdispered distribution of the worm count [41]. First, we checked the distribution of the WORM dependent variable. Despite the obvious overdispersion data, the results of Goodness-of-Fit tests showed that their distribution was neither Poisson $(p<0.0001)$ nor negative binomial $(p<0.0001)$. For this reason, we ranked the infection level (variable name WORMrank) using a previous studies' approach [8,9]: rank 0 (worm count: 0), rank 1 (worm count: 1-10), rank 2 (worm count: 11-100), rank 3 (worm count: 101-1000), and rank 4 (worm count: 1000<). After conversion, we conducted an ordinal logistic regression to determine the possible role of our explanatory variables in the formation of the E. multilocularis infection level. Valle et al. confirmed that the ordinal logistic regression could be superior to overdispersed and/or zero inflated parasitological data [42]. The data analysis was conducted by SPSS version 22 [43].

Supplementary Materials: The following are available online at https:/ / www.mdpi.com/article/ 10.3390 / parasitologia1030017/s1, Table S1: Result of molecular analysis of Echinococcus specimens identification, Table S2: Number of investigated hosts in different years, Table S3: Worm numbers in infected animals in different years, Table S4: The shooting coordinates of the collected carnivores, Table S5: Created environmental variables using the CORINE Land Cover 2018 database.

Author Contributions: Á.C., G.N. and T.H. conceived the study, collected the samples, accomplished the laboratory and data analysis, and prepared the manuscript. I.N. conducted and checked the statistical analysis. All authors have read and agreed to the published version of the manuscript.

Funding: This work was supported by the Hungarian National Research, Development and Innovation Office (Grant No.: 2020-4.1.1-TKP2020), the New National Excellence Program of the Ministry for Innovation and Technology from the source of the National Research, Development and Innovation Fund (Grant No.: ÚNKP-20-3-I-KE-7) and the Ministry of Human Resources (Grant No.: EFOP-3.6.3-VEKOP-16-2017-00005).

Institutional Review Board Statement: Not applicable. All specimens of this study originated from carcasses, which were harvested in the framework of a legal hunting management programme.

Informed Consent Statement: Not applicable. 
Data Availability Statement: Data are contained within the article and its supplementary material.

Conflicts of Interest: The authors have no conflict of interest to declare that are relevant to the content of this article.

\section{References}

1. Baumann, S.; Shi, R.; Liu, W.; Bao, H.; Schmidberger, J.; Kratzer, W.; Li, W.; Interdisciplinary Echinococcosis Working Group Ulm. Worldwide literature on epidemiology of human alveolar echinococcosis: A systematic review of research published in the twenty-first century. Infection 2019, 47, 703-727. [CrossRef]

2. European Food Safety Authority (EFSA); European Centre for Disease Prevention and Control. The European Union summary report on trends and sources of zoonoses, zoonotic agents and food-borne outbreaks in 2018. EFSA J. 2019, 17, e05926. [CrossRef]

3. European Food Safety Authority (EFSA); European Centre for Disease Prevention and Control. The European Union summary report on trends and sources of zoonoses, zoonotic agents and food-borne outbreaks in 2016. EFSA J. 2017, 15, e05077. [CrossRef]

4. Dezsényi, B.; Dubóczki, Z.; Strausz, T.; Csulak, E.; Czoma, V.; Káposztás, Z.; Fehérvári, M.; Somorácz, Á.; Csilek, A.; Oláh, A.; et al. Emerging human alveolar echinococcosis in Hungary (2003-2018): A retrospective case series analysis from a multi-centre study. BMC Infect. Dis. 2021, 21, 168. [CrossRef] [PubMed]

5. Oksanen, A.; Siles-Lucas, M.; Karamon, J.; Possenti, A.; Conraths, F.J.; Romig, T.; Wysocki, P.; Mannocci, A.; Mipatrini, D.; La Torre, G.; et al. The geographical distribution and prevalence of Echinococcus multilocularis in animals in the European Union and adjacent countries: A systematic review and meta-analysis. Parasites Vectors 2016, 9, 519. [CrossRef]

6. Hegglin, D.; Bontadina, F.; Deplazes, P. Human-wildlife interactions and zoonotic transmission of Echinococcus multilocularis. Trends Parasitol. 2015, 31, 167-173. [CrossRef]

7. Mueller, M.C.; Marx, M.; Peyerl-Hoffmann, G.; Kern, W.V. Spatial distribution and incidence trend of human alveolar echinococcosis in southwest Germany: Increased incidence and urbanization of the disease? Infection 2020, 48, 923-927. [CrossRef]

8. Tolnai, Z.; Széll, Z.; Sréter, T. Environmental determinants of the spatial distribution of Echinococcus multilocularis in Hungary. Vet. Parasitol. 2013, 198, 292-297. [CrossRef]

9. Balog, T.; Nagy, G.; Halász, T.; Csányi, E.; Zomborszky, Z.; Csivincsik, Á. The occurrence of Echinococcus spp. in golden jackal (Canis aureus) in southwestern Hungary: Should we need to rethink its expansion? Parasitol. Int. 2021, 80, 102214. [CrossRef]

10. Széll, Z.; Marucci, G.; Pozio, E.; Sréter, T. Echinococcus multilocularis and Trichinella spiralis in golden jackals (Canis aureus) of Hungary. Vet. Parasitol. 2013, 197, 393-396. [CrossRef]

11. Lalošević, D.; Lalošević, V.; Simin, V.; Miljević, M.; Čabrilo, B.; Bjelić Čabrilo, O. Spreading of multilocular echinococcosis in southern Europe: The first record in foxes and jackals in Serbia. Vojvodina Province. Eur. J. Wildl. Res. 2016, 62, 793-796. [CrossRef]

12. Sindičić, M.; Bujanić, M.; Štimac, M.; Martinković, M.; Tuškan, N.; Špehar, M.; Konjević, D. First identification of Echinococcus multilocularis in golden jackals in Croatia. Acta Parasitol. 2018, 63, 654-656. [CrossRef]

13. Wilson, K.; Bjørnstad, O.N.; Dobson, A.P.; Merler, S.; Pogalyen, G.; Randolphy, S.E.; Read, A.F.; Skopping, A. The Ecology of Wildlife Diseases, 1st ed.; Oxford University Press: Oxford, UK, 2002; pp. 6-44.

14. Lucherini, M.; Lovari, S. Habitat richness affects home range size in the red fox Vulpes vulpes. Behav. Process. 1996, 36, 103-105. [CrossRef]

15. Š́lek, M.; Červinka, J.; Banea, O.C.; Krofel, M.; Ćirović, D.; Selanec, I.; Penezić, A.; Grill, S.; Riegert, J. Population densities and habitat use of the golden jackal (Canis aureus) in farmlands across the Balkan Peninsula. Eur. J. Wildl. Res. 2014, 60, 193-200. [CrossRef]

16. Zaman, M.; Tolhurst, B.A.; Zhu, M. Den-site selection at multiple scales by the red fox (Vulpes vulpes subsp. montana) in a patchy human-dominated landscape. Glob. Ecol. Conserv. 2020, 23, e01136. [CrossRef]

17. Jacob, J.; Imholt, C.; Caminero-Saldaña, C.; Couval, G.; Giraudoux, P.; Herrero-Cófreces, S.; Horváth, G.; Luque-Larena, J.J.; Tkadlec, E.; Wymenga, E. Europe-wide outbreaks of common voles in 2019. J. Pest. Sci. 2020, 93, 703-709. [CrossRef]

18. Ritchie, E.G.; Elmhagen, B.; Glen, A.S.; Letnic, M.; Ludwig, G.; McDonald, R.A. Ecosystem restoration with teeth: What role for predators? Trends Ecol. Evol. 2012, 27, 265-271. [CrossRef]

19. Torretta, E.; Riboldi, L.; Costa, E.; Delfoco, C.; Frignani, E.; Meriggi, A. Niche partitioning between sympatric wild canids: The case of the golden jackal (Canis aureus) and the red fox (Vulpes vulpes) in north-eastern Italy. BMC Ecol. Evol. 2021, 21, 129. [CrossRef]

20. Kamler, J.F.; Stenkewitz, U.; Macdonald, D.W. Lethal and sublethal effects of black-backed jackals on cape foxes and bat-eared foxes. J. Mammal. 2013, 94, 295-306. [CrossRef]

21. Krofel, M.; Giannatos, G.; Ćirović, D.; Stoyanov, S.; Newsome, T.M. Golden jackal expansion in Europe: A case of mesopredator release triggered by continent-wide wolf persecution? Hystrix Ital. J. Mammal. 2017, 28, 9-15. [CrossRef]

22. Tsunoda, H.; Ito, K.; Peeva, S.; Raichev, E.; Kaneko, Y. Spatial and temporal separation between the golden jackal and three sympatric carnivores in a human-modified landscape in central Bulgaria. Zool. Ecol. 2018, 28, 172-179. [CrossRef]

23. Lanszki, J.; Heltai, M. Food preferences of golden jackals and sympatric red foxes in European temperate climate agricultural area (Hungary). Mammalia 2010, 74, 267-273. [CrossRef]

24. Scheinin, S.; Yom-Tov, Y.; Motro, U.; Geffen, E. Behavioural responses of red foxes to an increase in the presence of golden jackals: A field experiment. Anim. Behav. 2006, 71, 577-584. [CrossRef] 
25. Carricondo-Sanchez, D.; Odden, M.; Kulkarni, A.; Vanak, A.T. Scale-dependent strategies for coexistence of mesocarnivores in human-dominated landscapes. Biotropica 2019, 51, 781-791. [CrossRef]

26. Deplazes, P.; Rinaldi, L.; Alvarez Rojas, C.A.; Torgerson, P.R.; Harandi, M.F.; Romig, T.; Antolova, D.; Schurer, J.M.; Lahmar, S.; Cringoli, G.; et al. Global distribution of alveolar and cystic echinococcosis. Adv. Parasitol. 2017, 95, 315-493. [CrossRef] [PubMed]

27. Spassov, N.; Acosta-Pankov, I. Dispersal history of the golden jackal (Canis aureus moreoticus Geoffroy, 1835) in Europe and possible causes of its recent population explosion. Biodivers Data J. 2019, 7, e34825. [CrossRef] [PubMed]

28. Bannister-Tyrrell, M.; Verdonck, K.; Hausmann-Muela, S.; Gryseels, C.; Ribera, J.M.; Grietens, K.P. Defining micro-epidemiology for malaria elimination: Systematic review and meta-analysis. Malar. J. 2017, 16, 164. [CrossRef]

29. Goodin, D.G.; Jonsson, C.B.; Allen, L.J.S.; Owen, R.D. integrating landscape hierarchies in the discovery and modelling of ecological drivers of zoonotically transmitted disease from wildlife. In The Connections between Ecology and Infectious Disease, 1st ed.; Hurst, C.J., Ed.; Series Advances in Environmental Microbiology; Springer International Publishing: Cham, Switzerland, 2018; Volume 5, pp. 299-317.

30. Hofer, S.; Gloor, S.; Müller, U.; Mathis, A.; Hegglin, D.; Deplazes, P. High prevalence of Echinococcus multilocularis in urban red foxes (Vulpes vulpes) and voles (Arvicola terrestris) in the city of Zürich, Switzerland. Parasitology 2000, 120, 135-142. [CrossRef]

31. Traschel, D.; Deplazes, P.; Mathis, A. Identification of taeniid eggs in the faeces from carnivores based on multiplex PCR using targets in mitochondrial DNA. Parasitology 2007, 134, 911-920. [CrossRef]

32. Kulldorff, M.; Huang, L.; Pickle, L.; Duczmal, L. An elliptic spatial scan statistic. Stat. Med. 2006, 25, 3929-3943. [CrossRef]

33. Kjærulff, T.M.; Ersbøll, A.K.; Gislason, G.; Schipperijn, J. Geographical clustering of incident acute myocardial infarction in Denmark: A spatial analysis approach. Spat. Spatiotemporal Epidemiol. 2016, 19, 46-59. [CrossRef] [PubMed]

34. Andreasen, A.M.; Dehlendorff, P.B.; Knudtzen, F.C.; Bødker, R.; Jung Kjær, L.; Skarphedinsson, S. Spatial and temporal patterns of Lyme Neuroborreliosis on Funen, Denmark from 1995-2014. Sci. Rep. 2020, 10, 7796. [CrossRef]

35. Main, M.T.; Davis, R.A.; Blake, D.; Mills, H.; Doherty, T.S. Human impact overrides bioclimatic drivers of red fox home range size globally. Divers. Distrib. 2020, 26, 1083-1092. [CrossRef]

36. Torretta, E.; Dondina, O.; Delfoco, C.; Riboldi, L.; Orioli, V.; Lapini, L.; Meriggi, A. First assessment of habitat suitability and connectivity for the golden jackal in north-eastern Italy. Mammal. Biol. 2020, 100, 631-643. [CrossRef]

37. Reiczigel, J.; Abonyi-Tóth, Z.; Singer, J. An exact confidence set for two binomial proportions and exact unconditional confidence intervals for the difference and ratio of proportions. Comput. Stat. Data Anal. 2008, 52, 5046-5053. [CrossRef]

38. Reiczigel, J.; Marozzi, M.; Fabian, I.; Rozsa, L. Biostatistics for parasitologists-A primer to Quantitative Parasitology. Trends Parasitol. 2019, 35, 277-281. [CrossRef] [PubMed]

39. Marques de Sá, J.P. Applied Statistics Using SPSS, STATISTICA, MATLAB and R, 2nd ed.; Springer: Berlin/Heidelberg, Germany, 2007; pp. 303-314.

40. Swets, J.A. Measuring the accuracy of diagnostic systems. Science 1988, 240, 1285-1293. [CrossRef]

41. Ziadinov, I.; Deplazes, P.; Mathis, A.; Mutunova, B.; Abdykerimov, K.; Nurgaziev, R.; Torgerson, P.R. Frequency distribution of Echinococcus multilocularis and other helminths of foxes in Kyrgyzstan. Vet. Parasitol. 2010, 171, 286-292. [CrossRef] [PubMed]

42. Valle, D.; Ben Toh, K.; Laporta, G.Z.; Zhao, Q. Ordinal regression models for zero-inflated and/or over-dispersed count data. Sci. Rep. 2019, 9, 3046. [CrossRef]

43. IBM Corp. IBM SPSS Statistics for Windows, Version 22.0; IBM Corp: Armonk, NY, USA, 2013. 